\title{
ГЕОХИМИЯ УРАНА И ТОРИЯ В ДОННЫХ ОТЛОЖЕНИЯХ МАЛЫХ ИСКУССТВЕННЫХ ВОДОЕМОВ И ОЗЕР НА ТЕРРИТОРИИ ЮГА ТОМСКОЙ ОБЛАСТИ
}

\author{
Иванов Андрей Юрьевич', \\ Ivanov-13@mail.ru \\ Арбузов Сергей Иванович', \\ Siarbuzov@mail.ru \\ 1 Национальный исследовательский Томский политехнический университет, \\ Россия, 635050, г. Томск, пр. Ленина, 30.
}

\begin{abstract}
Актуальность. Радиоактивные элементы являются эффективными маркерами состояния донных отложений малых водоемов и озер. Актуальность проблемы определяется слабой изученностью радиоактивных элементов в донных осадках озер и искусственных водоемов на территории юга Томской области.

Цель: изучение радиогеохимических особенностей донных осадков озер и искусственных водоемов на территории юга Томской области.

Объектом исследования являются донные отложения малых водоемов и озер юга Томской области.

Методы: детальное опробование донных отложений малых водоемов, многоэлементный инструментальный нейтронно-активационный анализ, обработка и интерпретация полученных данных методами прикладной статистики.

Результаты. Проведены радиогеохимические исследования донных осадков озер и искусственных водоемов на территории юга Томской области. Сделаны оценки среднего содержания урана и тория в донных осадках озер и искусственных водоемов на территории юга Томской области. В процессе исследований установлено, что содержание как урана, так и тория зависит от минерального типа донных осадков. Наименьшие концентрации урана были установлены в торфянистом типе, а наиболее высокие концентрации - в терригенном типе донных осадков. Установлено две зоны с повышенным содержанием урана. Первая зона пространственно приурочена к Кожевниковскому и Шегарскому районам Томской области. В этом районе выделяется Осиновско-Бабарыкинская радиогеохимическии аномальная зона повышенного накопления урана, которая очень четко прослеживается в субмеридиональном направлении. В пределах Кожевниковского района она может быть связана с разгрузкой подземных вод в зоне Колыванского разлома. В Шегарском районе повышенные содержания урана пространственно приурочены К гранитоидам позднепалеозойского фундамента. Вторая зона накопления урана простирается вдоль южного обрамления Западно-Сибирской плиты в пределах Кузнецко-Алатаусского блока.
\end{abstract}

\section{Ключевые слова:}

Донные отложения, уран и торий, радиогеохимические исследования, зона аномального накопления урана, вертикальное распределение.

\section{Введение}

Современная радиационная обстановка территории может складываться из природных и техногенных факторов. К природным факторам относится наличие радиогеохимически специализированных пород на территории, например, рудопроявлений и месторождений урана (Трубачевское, Пригородное, Малиновское и т. д.), которые расположены в южном обрамлении Западно-Сибирской плиты [1]. К техногенным факторам относится поступление радиоактивных элементов в окружающую среду, связанное с производственной деятельностью, например со сжиганием углей на ТЭС. Подтверждение тому - результаты многолетних исследований на территории Томского района и г. Томска. Нельзя исключать и влияние предприятий атомной промышленности как потенциального источника поступления радиоактивных элементов в окружающую среду $[2,3]$. Хотя в последнем случае такие поступления успешно распознаются по специфике изотопного состава радионуклидов.

Донные отложения малых водоемов традиционно используются в качестве маркера для выявления состава, масштаба и интенсивности техногенного загрязнения, а также природного фактора для оценки геохимической специализации терри- тории [4-11]. Преимущественно это обуславливается тем, что донные осадки малых водоемов отражают геохимические особенности сопряженных территорий, так как являются конечным звеном местных ландшафтных сопряжений.

Специализированные геохимические исследования донных отложений относятся к числу наиболее актуальных современных методов изучения экосистем. При детальном изучении колонки донных осадков это позволяет проследить эволюционные изменения состава окружающей среды, при этом выделить временные интервалы, в какой момент происходило наиболее интенсивное поступление в среду обитания человека радиоактивных элементов, получить информацию о радиационном фоне и возможных природных или техногенных аномалиях $[12,13]$.

Как правило, малые водоемы образуются по одному и тому же природному пути: изначально формируется чаша, в которой затем происходит осадконакопление. Именно поэтому схема образования донных осадков является практически идентичной для всех водоемов. По современным данным, для изучения процесса осадконакопления в малых водоемах следует проследить путь осадкообразования от мест формирования исходного материала 
осадка до осаждения его в исследуемом водоеме [14].

Скорость накопления донных отложений в различных водоемах неодинакова, но известно, что в среднем их мощность за последние столетия составляет несколько десятков сантиметров [12]. Детальное секционное опробование разреза донных отложений относительно небольшой мощности позволяет изучить природу их накопления за достаточно протяженный период времени, изучить закономерности распределения и проследить динамику поступления радиоактивных элементов в донные отложения [15]. Для решения этих задач авторами было выполнено детальное опробование и изучены основные закономерности пространственно-временного распределения урана и тория в донных осадках озер и искусственных водоемов на территории юга Томской области.

Цель работы: изучение радиогеохимических особенностей донных осадков озер и искусственных водоемов на территории юга Томской области для выявления их радиогеохимической специализации.

\section{Характеристика объектов исследования}

Исследованные водоемы находятся на юге и юго-востоке Томской области. Рассматриваемая территория расположена в пределах южнотаежной подзоны на границе с лесостепной зоной и характеризуется существенной дифференциацией гидрологических условий: в правобережной части водосбора реки Обь - модули водного стока составляют в целом более 4 л/(с·км²), а в левобережной - менее 4 л/(c·км²) [16]. Водоемы района исследования в целом гидрологически изучены слабо. Наиболее полные сведения об объемах и химическом составе воды в озерах и водохранилищах приведены О.Г. Савичевым [16]. Озерные котловины в основном относятся к типу водно-эрозионных и водно-аккумуля- тивных, в случае болот - ко вторичным, возникшим в результате формирования вторичной гидрографической сети на болотах. Искусственные водоемы - чаще всего речные долинные или в долинах временных водотоков. Средний полный объем водохранилищ - 109 тыс. м $^{3}$, средняя площадь акватории - 0,061 км². Озерные воды (и воды водохранилищ) в целом характеризуются как пресные со средней минерализацией, по величине $\mathrm{pH}$ - от кислых до слабощелочных, обычно содержат значительное количество органического вещества, продуктов его разложения и железа [16].

Для опробования были выбраны естественные слабопроточные водоемы и искусственные водохранилища (пруды), возраст которых составлял не менее 20 лет. Средняя их глубина обычно не превышает 3 м. Донные осадки озер и искусственных водоемов на территории юга Томской области имеют различный состав и представлены в основном илистыми глинисто-кластогенными осадками, peже органогенными торфянистыми отложениями и карбонатными сапропелями. В целом преобладают терригенные илистые отложения.

Всего опробовано 299 озер и искусственных водоемов (рис. 1).

\section{Методика исследований}

Опробование выполнено с помощью специального сапропелевого бура, позволяющего извлекать полный разрез донных отложений без нарушения сплошности. После извлечения полученный керн делился на интервалы. Длина интервала опробования зависела от поставленной задачи и изменялась от 1 см до 1 м. Всего было отобрано 618 проб.

Все отобранные пробы донных отложений подвергнуты единой процедуре пробоподготовки, заключавшейся в их просушке в естественных условиях, дроблении и истирании до 200 меш.

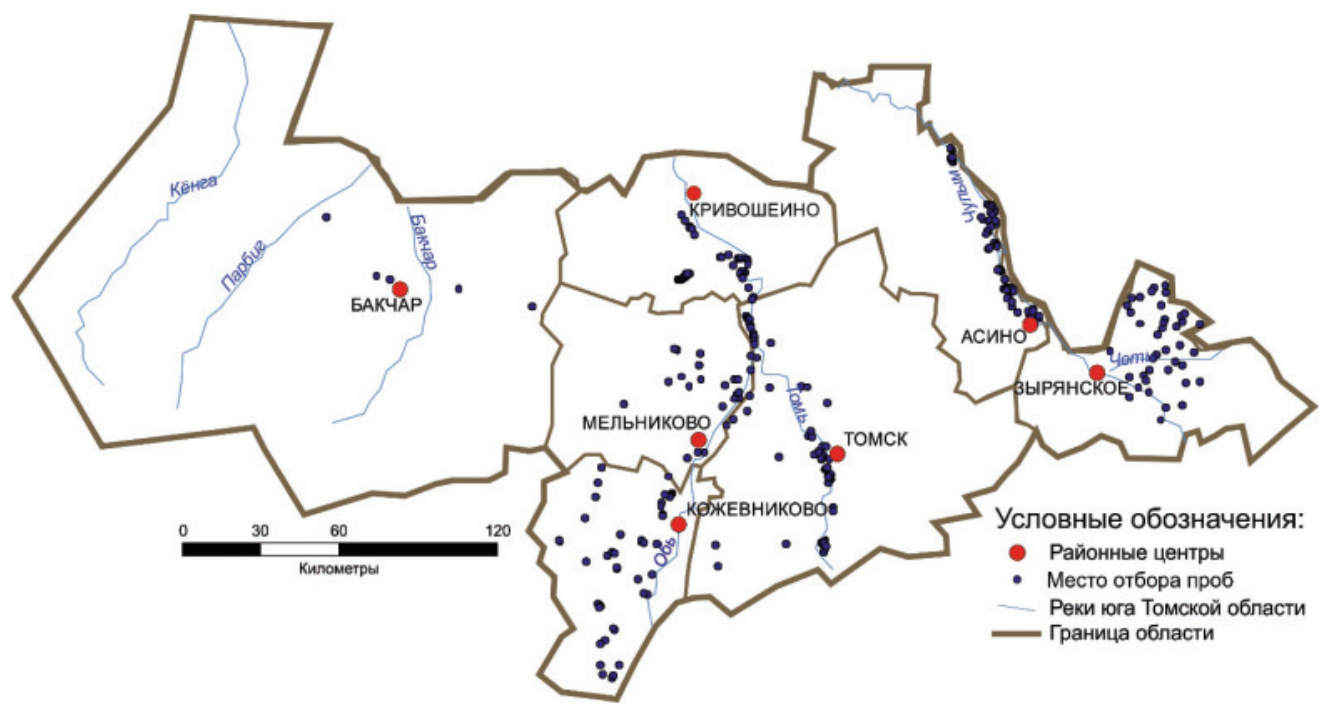

Pис. 1. Схема разлещения исследуелых водоелов на территории юга Толского области

Fig. 1. Scheme of the studied reservoirs location in the south of Tomsk region 
Исследование химического состава на 28 элементов выполнено методом инструментального нейтронно-активационного анализа (ИНАА) в лаборатории ядерно-геохимических исследований Национального исследовательского Томского политехнического университета (исполнители А.Ф. Судыко и Л.В. Богутская). Качество аналитических работ контролировалось путем сравнения со стандартными образцами [17] (табл. 1).

Таблица 1. Определение урана и тория в стандартных образцах методом ИНАА [17]

Table 1. Determination of uranium and thorium in standard samples by INAA

\begin{tabular}{|c|c|c|c|c|}
\hline \multirow{5}{*}{$\begin{array}{c}\text { Стандартный } \\
\text { образец } \\
\text { Standard sample }\end{array}$} & \multicolumn{2}{|c|}{ Уран/Uranium } & \multicolumn{2}{|c|}{ Торий/Thorium } \\
\hline & \multicolumn{4}{|c|}{$\Gamma / \mathrm{T}(\mathrm{g} / \mathrm{t})$} \\
\hline & Паспортные & & Паспорт- & \\
\hline & данные & ЯгЛ тПУ & ные данныє & ЯГЛ ТПУ \\
\hline & $\begin{array}{l}\text { Passport } \\
\text { data }\end{array}$ & NGL TPU & $\begin{array}{c}\text { Passport } \\
\text { dat }\end{array}$ & NGL TPU \\
\hline $\begin{array}{l}\text { Зола угля (Coal ash) } \\
\text { ЗУК-1 ГСО 7125-94 }\end{array}$ & $3,3 \pm 0,4$ & $3,2 \pm 0,71$ & $5,8 \pm 1,0$ & $5,6 \pm 0,23$ \\
\hline $\begin{array}{c}\text { Байкальский ил } \\
\text { (Baikal silt) Бил-1 } \\
\text { ГC0 7126-94 }\end{array}$ & $12,0 \pm 1,1$ & $12,0 \pm 0,83$ & $12,7 \pm 1,3$ & $12,7 \pm 0,34$ \\
\hline $\begin{array}{l}\text { Mopские отложения } \\
\text { (Marine sediments) } \\
\text { IAEA } 315\end{array}$ & $\begin{array}{c}3,20 \\
(2,40-3,50)\end{array}$ & $3,47 \pm 0,17$ & $\begin{array}{c}6,64 \\
(6,24-6,92)\end{array}$ & $6,50 \pm 0,35$ \\
\hline $\begin{array}{l}\text { Морские отложения } \\
\text { (Marine sediments) } \\
\text { IAEA SD-M-2/TM }\end{array}$ & $\begin{array}{c}2,49 \\
(1,44-3,5)\end{array}$ & $2,27 \pm 0,19$ & $\begin{array}{c}8,15 \\
(7,2-9,1)\end{array}$ & $8,69 \pm 0,29$ \\
\hline $\begin{array}{c}\text { Гранат-биотитовый } \\
\text { плагиогнейс } \\
\text { (Garnet-biotite } \\
\text { plagiogneiss) ГБП-1 }\end{array}$ & $0,8 \pm 0,1$ & $0,72 \pm 0,14$ & $11,3 \pm 1,5$ & $11,2 \pm 0,40$ \\
\hline
\end{tabular}

Также был проведен внутренний контроль качества аналитических работ путем повторного анализа дубликатов проб. На рис. 2 приведены результаты анализа проб донных отложений пруда в д. Осиновка, выполненные в 2004 и в 2008 гг., которые показывают хорошую воспроизводимость.

\section{Результаты исследований и их обсуждение}

В результате исследований было установлено, что средние содержания урана $(3,6$ г/т) и тория $(7,0$ г/т) близки к средним оценкам для донных отложений Сибири [12], хотя и несколько выше их. Торий-урановое отношение близко к кларку для осадочных пород [18].

Таблица 2. Среднее содержание урана и тория в донных осадках малых водоемов Томской области, г/m

Table 2. Mean content of uranium and thorium in the sediments of small reservoirs of Tomsk region, $g / t$

\begin{tabular}{|c|c|c|c|c|c|c|}
\hline \multirow{2}{*}{$\begin{array}{c}\text { Регион } \\
\text { (район, объект) } \\
\text { исследования } \\
\text { Region } \\
\text { of the research }\end{array}$} & \multirow{2}{*}{\begin{tabular}{|c|} 
Количество \\
водоемов \\
Number \\
of water \\
reservoirs \\
\end{tabular}} & \multicolumn{2}{|l|}{ elU } & \multicolumn{2}{|l|}{ elTh } & \multirow[b]{2}{*}{$\mathrm{Th} / \mathrm{U}$} \\
\hline & & $\begin{array}{l}\text { Содержа- } \\
\text { ние } \\
\text { Content }\end{array}$ & $\begin{array}{l}V \\
\%\end{array}$ & $\begin{array}{c}\text { Содержа- } \\
\text { ние } \\
\text { Content }\end{array}$ & $\begin{array}{l}V, \\
\%\end{array}$ & \\
\hline $\begin{array}{l}\text { Томская область, } \\
\text { в том числе районы: } \\
\text { Tomsk region, } \\
\text { including districts: }\end{array}$ & 299 & $\frac{3,6 \pm 0,1}{0,5 \ldots 35,2}$ & 95 & $\frac{7,0 \pm 0,1}{0,4 \ldots 13,7}$ & 33 & 1,9 \\
\hline $\begin{array}{l}\text { Томский } \\
\text { Tomsk }\end{array}$ & 46 & $\frac{3,6 \pm 0,1}{0,6 \ldots 6,6}$ & 24 & $\frac{6,5 \pm 0,1}{0,4 \ldots 8,9}$ & 11 & 1,8 \\
\hline $\begin{array}{l}\text { Кожевниковский } \\
\text { Kozhevnikovo }\end{array}$ & 50 & $\underline{4,1 \pm 0,1}$ & 112 & $\frac{7,5 \pm 0,1}{2,2 \ldots 11,5}$ & 29 & 1,8 \\
\hline $\begin{array}{l}\text { Бакчарский } \\
\text { Bakchar }\end{array}$ & 6 & $\frac{0,82 \pm 0,1}{0,5 \ldots 2,1}$ & 82 & $\frac{7,2 \pm 0,1}{5,1 \ldots 8,6}$ & 11 & 8,7 \\
\hline $\begin{array}{l}\text { Шегарский } \\
\text { Shegarsky }\end{array}$ & 30 & $\frac{3,8 \pm 0,1}{1,7 \ldots 31}$ & 146 & $\frac{8,3 \pm 0,1}{1,3 \ldots 13,7}$ & 38 & 2,2 \\
\hline $\begin{array}{l}\text { Зырянский } \\
\text { Zyryansky }\end{array}$ & 40 & $\frac{3,2 \pm 0,1}{0,5 \ldots 12}$ & 65 & $\frac{7,7 \pm 0,1}{4,3 \ldots 11,3}$ & 21 & 2,4 \\
\hline $\begin{array}{l}\text { Асиновский } \\
\text { Asino }\end{array}$ & 68 & $\frac{3,1 \pm 0,1}{1,5 \ldots 6,7}$ & 38 & $\frac{7,8 \pm 0,1}{1,2 \ldots 12,9}$ & 24 & 2,5 \\
\hline $\begin{array}{l}\text { Кривошеинский } \\
\text { Krivosheino }\end{array}$ & 59 & $\frac{2,6 \pm 0,1}{0,5 \ldots 5,3}$ & 54 & $\frac{7,2 \pm 0,1}{3,8 \ldots 9,9}$ & 16 & 2,7 \\
\hline
\end{tabular}

Примечание: $V$ - коэффициент вариации, \%; в зналенателе-лаксимальные и линимальные значения; в числителе - среднее значение; \pm - ошибка определения среднего; жирныл выделены значения урана выше среднего для Томской области

Note: $V$ is the coefficient of variation, \%; in the denominator - maximum and minimum values; in the numerator - average; \pm - error in determining the average; bold highlighted uranium values above the average for the Tomsk region.

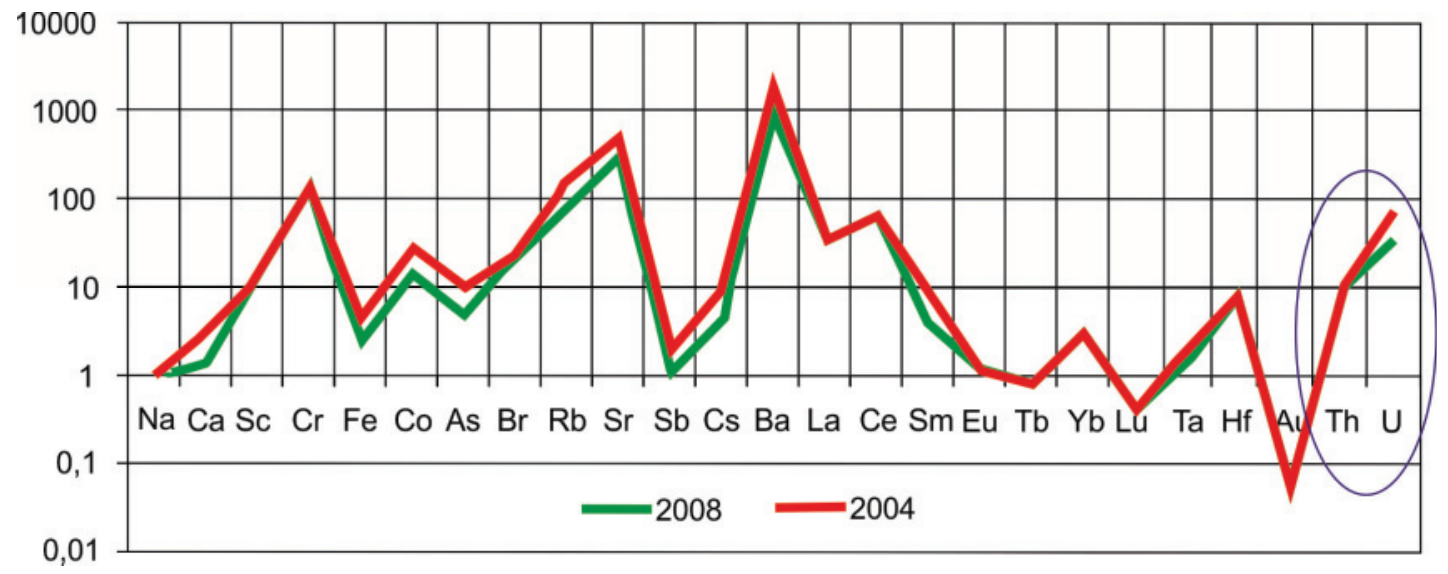

Pис. 2. Внутренний контроль ИНАА г/m (2004, 2008 г. контроля)

Fig. 2. Internal control of INNA g/t $(2004,2008)$ 
Анализ полученных данных показывает, что уран характеризуется достаточно неравномерным распределением (коэффициент вариации $95 \%$ ). Исключение составляют Томский и Асиновский районы, распределение урана в донных отложениях которых достаточно равномерно (коэффициент вариации 24 и 38 \% соответственно). Коэффициент вариации распределения тория при этом достаточно выдержан и не превышает 38 \% (табл. 2).

Как следует из табл. 2, полученные средние оценки содержания урана и тория в донных осадках озер и искусственных водоемов Асиновского, Зырянского и Кривошеинского районов очень схожи.

Шегарский и Кожевниковский район характеризуются более высокими концентрациями урана. В некоторых водоемах содержание урана превышает 20 г/т и в отдельных сечениях в разрезе донных отложений достигает максимума - 60 г/т. Содержание тория при высоких концентрациях урана выдержано, что указывает на его накопление преимущественно в составе обломочной фракции. На преимущественно кластогенное накопление тория в донных отложениях указывает и его содержание на уровне кларка для осадочных пород [18] при низкой дисперсии распределения.

Аномально низкое содержание урана при высоком торий-урановом отношении отмечено в донных отложениях водоемов Бакчарского района.

Содержание урана и тория в донных осадках водоемов и озер непосредственно зависит от их минерального состава, который, в свою очередь, определяется особенностями терригенной составляющей впадающих в него водотоков [12] и, вероятнее всего, разгрузкой подземных вод трещинного типа [15]. Анализ данных позволяет отметить, что в разных типах донных отложений среднее содержание как урана, так и тория значительно различается. Было выделено три типа осадков: торфянистый, терригенный и карбонатный. Терригенный тип донных осадков отличается повышенными содержаниями урана и тория относительно торфянистого и карбонатного и очень близок к среднему содержанию в осадочных горных породах [18]. Торфянистый тип осадков, относительно двух других изученных типов, заметно отличается высоким $\mathrm{Th} / \mathrm{U}$ отношением, но обладает пониженным содержанием урана (табл. 3).

Во всех изученных озерах и искусственных водоемах донные осадки имеют смешанную природу радиоактивности, это отчетливо видно из графика, отражающего положение донных отложений в координатах Th-U (рис. 3).

Донные осадки изученных водоемов обладают достаточно выдержанным $\mathrm{Th} / \mathrm{U}$ отношением и очень близки к средним оценкам их содержания в осадочных породах [18]. Это соответствует нормальному $\mathrm{Th} / \mathrm{U}$ отношению в большинстве типов геологических образований земной коры. Исключением является Бакчарский район, который отличается достаточно высоким торий-урановым отношением $(\mathrm{Th} / \mathrm{U}>5)$. Такие значения свойственны для районов с проявлением ториеносных геологических образований [19]. Томский и Кожевниковский районы характеризуются существенно более низким $\mathrm{Th} / \mathrm{U}$ отношением $(\mathrm{Th} / \mathrm{U}<2)$, что, скорее всего, указывает на накопление части урана за счет сорбции растворенного металла из питающих вод.

Таблииа 3. Средние содержания урана и тория в различных типах донных отложений озер юга Томской области, г/m

Table 3. Mean contents of uranium and thorium in different types of lake sediments in the south of Tomsk region, $g / t$

\begin{tabular}{|c|c|c|c|}
\hline $\begin{array}{c}\text { Состав отложений } \\
\text { Composition of the sediments }\end{array}$ & elU & elTh & $\mathrm{Th} / \mathrm{U}$ \\
\hline $\begin{array}{l}\text { Tерригенные (421 проба) } \\
\text { Terrigenous (421 samples) }\end{array}$ & $\frac{4,0 \pm 0,1}{0,5 \ldots 35,2}$ & $\frac{7,2 \pm 0,1}{2,8 \ldots 13,7}$ & 1,8 \\
\hline $\begin{array}{l}\text { Карбонатные (129 проб) } \\
\text { Carbonate (129 samples) }\end{array}$ & $\underline{2,8 \pm 0,1}$ & $\frac{3,6 \pm 0,1}{0,4 \ldots 10,2}$ & 1,3 \\
\hline $\begin{array}{l}\text { Topфянистые ( } 68 \text { проб) } \\
\text { Peaty ( } 68 \text { samples) }\end{array}$ & $\frac{1,6 \pm 0,1}{0,4 \ldots 5,5}$ & $\frac{4,4 \pm 0,1}{1,4 \ldots 9,5}$ & 2,8 \\
\hline $\begin{array}{l}\text { Среднее для Сибири* } \\
\text { Average for Siberia }\end{array}$ & $\frac{2,9}{0,0 \ldots 34}$ & $\underline{0,4 . . .11,9}$ & 1,7 \\
\hline $\begin{array}{l}\text { Кларк *\% } \\
\text { Mean concentration for sedimentary rocks }\end{array}$ & 3,4 & 7,7 & 2,2 \\
\hline
\end{tabular}

Примечание: в зналенателе - минимальные и максимальные значения; в числителе - среднее значение; \pm - ошибка определения среднего; *- среднее для Сибири [12]; ** - кларк для осадочных пород [18]

Note: in the denominator - minimum and maximum values; in the numerator-average value; \pm - error in determining the average; *-average for Siberia [12]; **-Clark for sedimentary rocks [18].

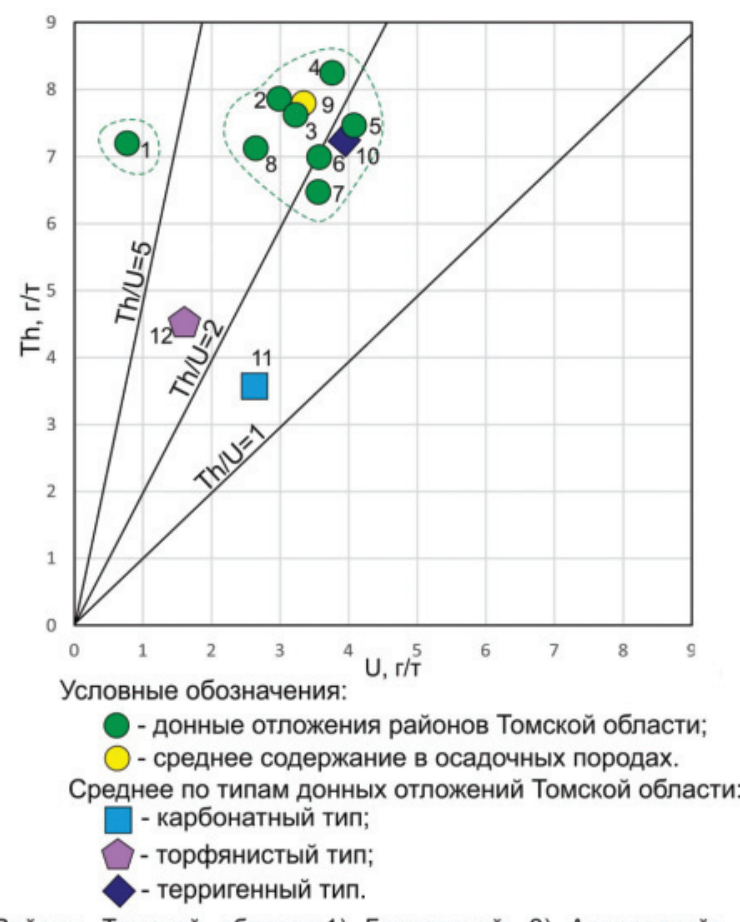

Районы Томской области:1) Бакчарский; 2) Асиновский 3) Зырянский; 4) Шегарский; 5) Кожевниковский; 6) среднее для Томской области; 7) Томский; 8) Кривошеинский 9) среднее содержание в осадочных породах по Григорьеву Н.А.; типы донных отложений: 10) терригенный; 11) карбонатный; 12) торфянистый.

Pис. 3. Радиогеохимическая характеристика донных осадков малых водоемов юга Томской области и осадочных пород

Fig. 3. Radiogeochemical characteristics of the sediments of small reservoirs in the south of Tomsk region and sedimentary rocks 


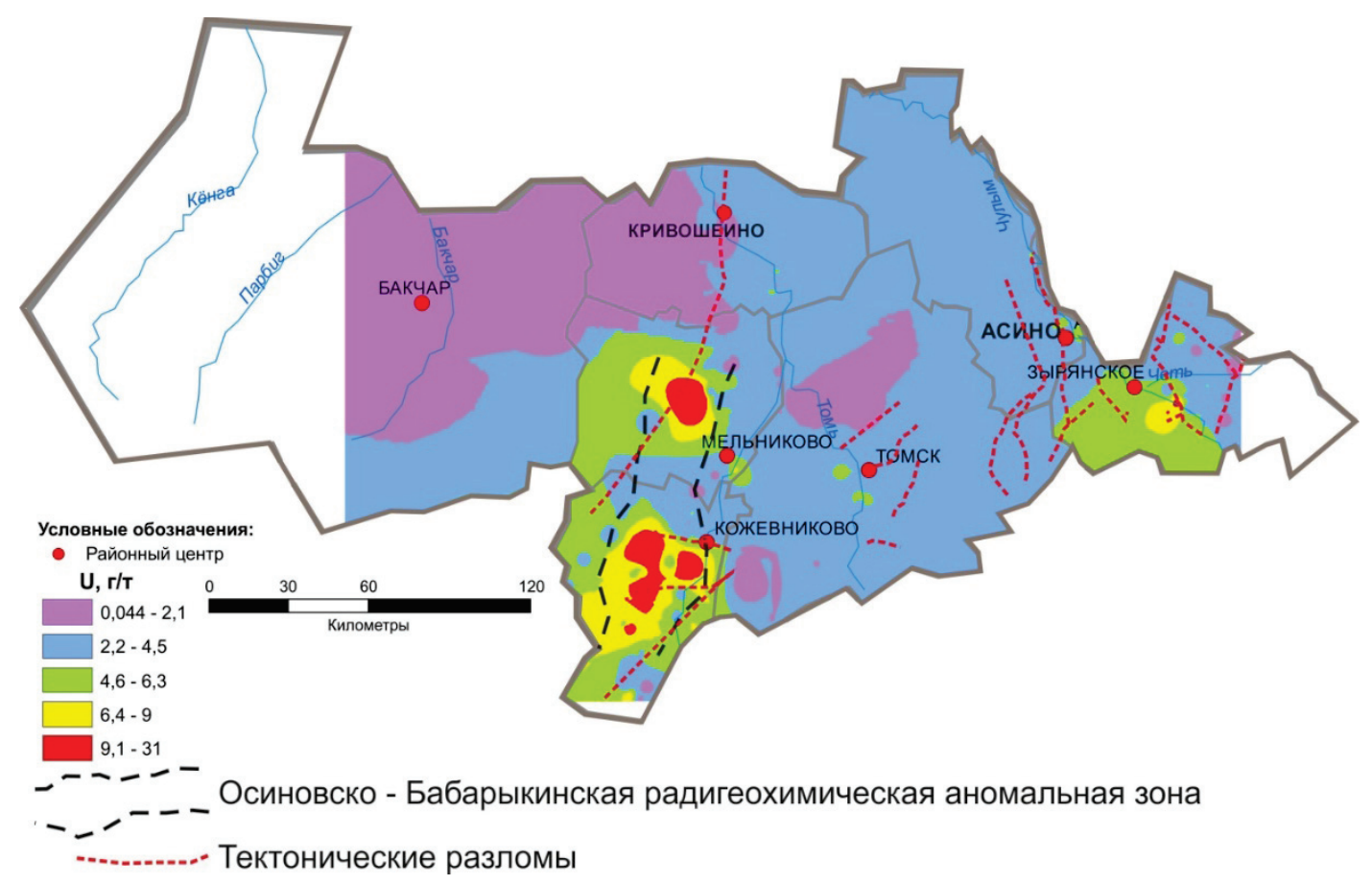

Pис. 4. Схематическая карта распределения $U(2 / m)$ в донных осадках малых водоемов юга Томской области

Fig. 4. Schematic map of $U(\mathrm{~g} / \mathrm{t})$ distribution in the sediments of small water reservoirs in the south of Tomsk region

Детальный анализ пространственного распределения урана в донных осадках изученных водоемов позволил оконтурить две зоны с повышенными уровнями его накопления (рис. 4).

Первая зона представлена ореолом высоких содержаний урана в южном блоке Кузнецкого Алатау в обрамлении Западно-Сибирской плиты (Зырянский район). Такая закономерность его распределения ранее отмечена во многих работах $[1,20]$.

Вторая зона повышенных концентраций урана откартирована в пределах двух районов Томской области (Кожевниковский и Шегарский) и представляет собой ореолы субмеридионального простирания. В пределах этих районов на фоне достаточно однородного распределения урана в донных отложениях изученных водоемов отчетливо выделяется Осиновско-Бабарыкинская радиогеохимическая аномальная зона, которая характеризуется повышенным концентрациями урана и пониженным $\mathrm{Th} / \mathrm{U}$ отношением (рис. 4). Урановая аномалия ранее уже была отмечена в поверхностных водах и почвах в Кожевниковском районе Томской области [19].

Высокие содержания урана в донных осадках Зырянского района хорошо согласуются с наличием контрастных аномалий в зонах окисления бурых углей Козульского, Усманского и Яйского месторождений [21].

Пространственное распределение тория также достаточно неоднородно (рис. 5).

Контрастных аномалий у тория не выявляется, но так же, как и для урана, можно оконтурить зоны с относительно высокими его концентрациями. Од- на зона простирается вдоль долины реки Чулым на востоке региона. Вторую зону можно проследит вдоль долины реки Оби в пределах Осиновско-Бабарыкинской радиогеохимически аномальной зоны.

В распределении Th/U отношения повышенными значениями характеризуется северная и северо-западная часть изученной области, наименьшими - южная и юго-восточная, в зоне обрамления Западно-Сибирской плиты (рис. 6).

На рис. 7 изображен график, который отражает положение донных осадков в координатах $\mathrm{Th}-\mathrm{U}$ всех изученных водоемов юга Томской области (рис. 7). Th/U-отношение в донных осадках изученных водоемов в основном близко к 2 . Так как донные осадки выделенной Осиновско-Бабарыкинской аномальной зоны отличаются достаточно низким $\mathrm{Th} / \mathrm{U}$ отношением, $\mathrm{Th} / \mathrm{U} \leq 1$, это говорит о том, что идет преимущественно концентрирование урана по сравнению с торием (рис. 7). Одним из более вероятных способов концентрации урана в донных осадках считается его сорбция на органическом веществе. Торий отличается существенно более низкой миграционной способностью в водах в условиях зоны гипергенеза по сравнению с ураном.

Повышенные содержания урана в ОсиновскоБабарыкинской радиогеохимически аномальной зоне могут быть связаны с наличием уранового оруденения в пределах буготакского разлома, сопровождающегося гидротермалитами с радиоактивностью 20-330 мкР/ч, на фоне $3-16$ мкР/ч для основных типов осадочных пород района. Литогеохимическая аномалия совмещена с гидрогеохимической. Эти воды служат источником урана для 


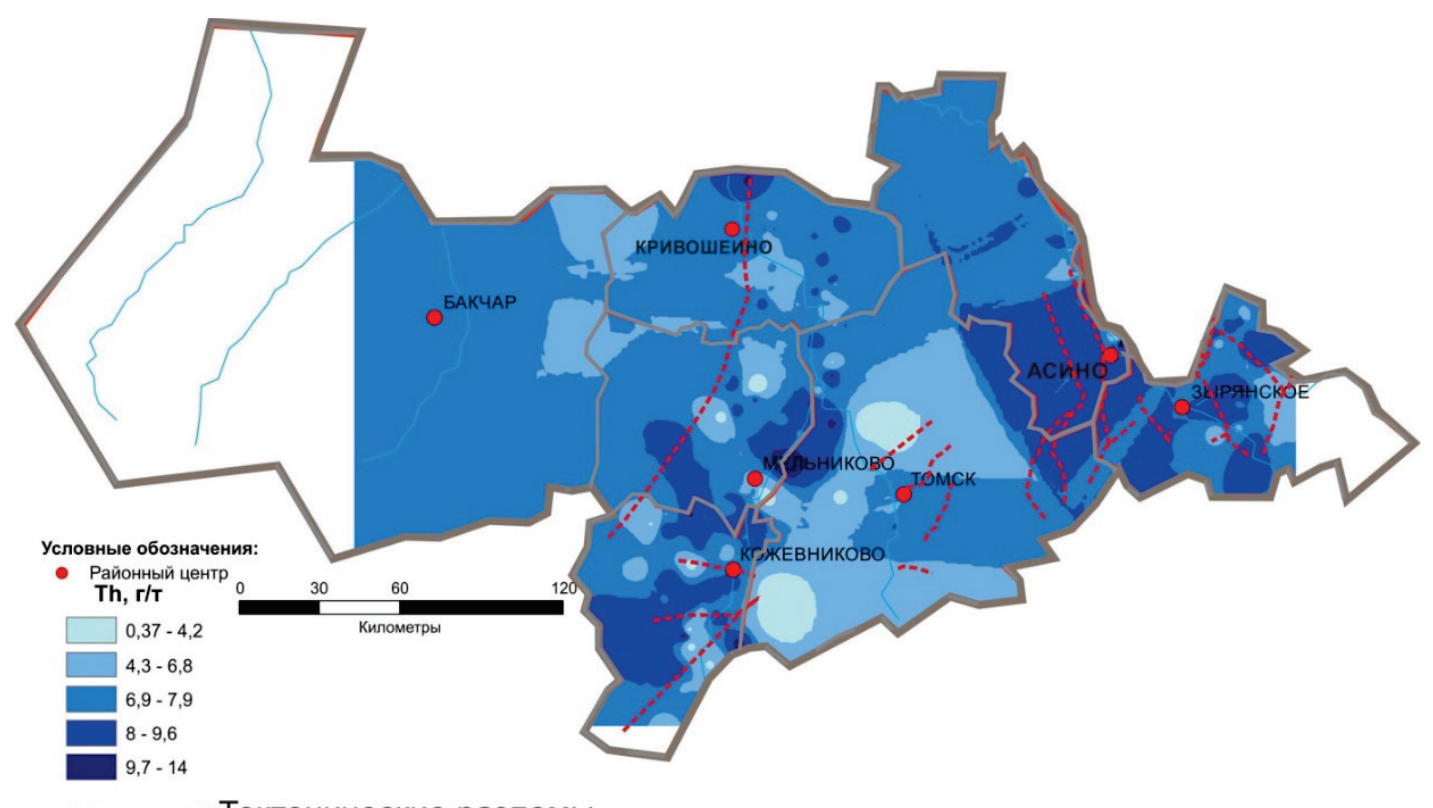

Тектонические разломы

Puc. 5. Схематическая карта распределения Тh в донных осадках малых водоемов юга Томской области, г/m

Fig. 5. Schematic map of Th distribution in the sediments of small water reservoirs in the south of Tomsk region, $g / t$

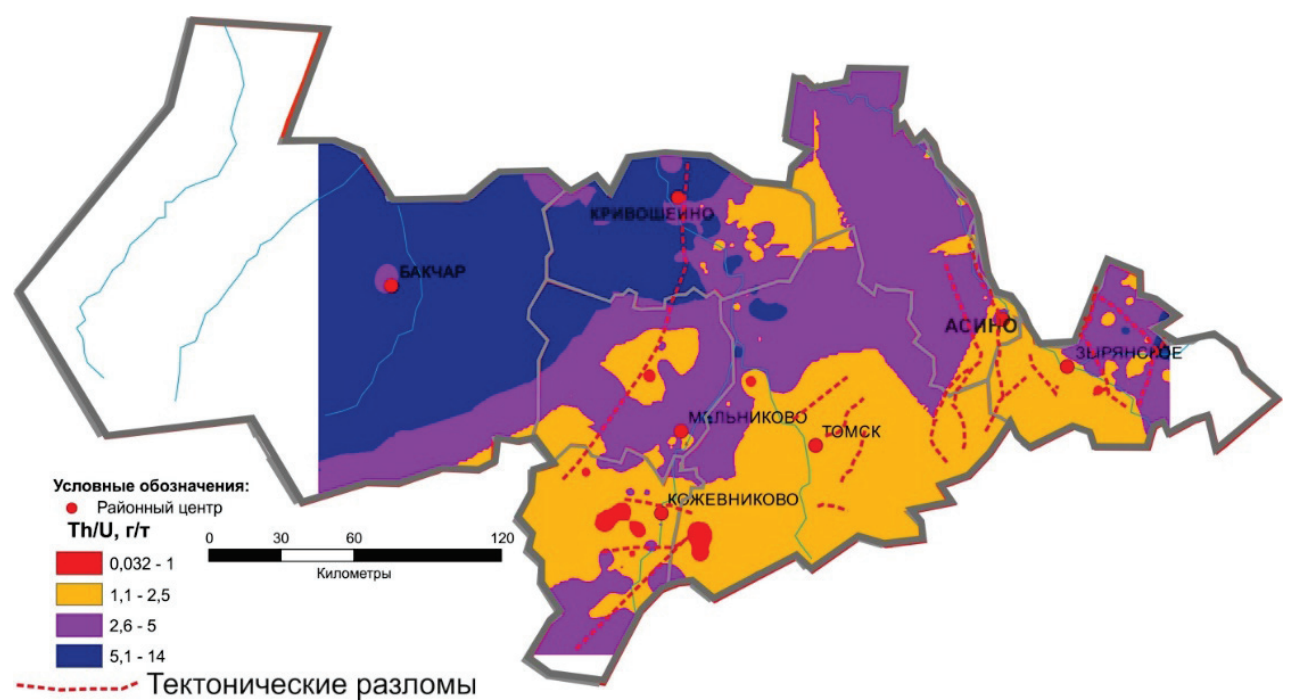

Pис.6. Схематическая карта пространственной изменчивости величины Th/U отношения в донных осадках малых водоемов юга Томской области, $2 / m$

Fig. 6. Schematic map of the $T h / U$ ratio spatial variability in the sediments of small water reservoirs in the south of Tomsk region, $g / t$

торфяников, в которых он накапливается за счет биогенной аккумуляции и сорбции в илистой фракции донных осадков [22].

Повышенные концентрации урана могут быть связаны с тем, что происходит выветривание радиогеохимически специализированных комплексов горных пород в Кузнеко-Алатаусской и ТомьКолыванской складчатых зонах, снос и концентрирование данного элемента в осадочных отложениях вдоль южного обрамления Западно-Сибирской плиты. Подтверждением аномальных концентраций урана в донных отложениях является схожий механизм накопления аномальных концентраций урана в многочисленных торфяниках региона [22].

Возможной причиной повышенного содержания урана может быть разгрузка подземных вод в зоне Колыванского разлома в Колывань-Томской складчатой зоне, где в зонах тектонических нарушений в подземных водах установлены аномальные концентрации урана (до $\left.5,4 \cdot 10^{-5} \Gamma / л\right)$ [23]. Как известно, подземные воды, взаимодействуя с урановыми концентрациями, могут извлекать уран из пород либо путем растворения урановых минера- 
лов, либо путем выщелачивания урана, находящегося в рассеянном состоянии. Вследствие хорошей миграционной способности уран может переносится на большие расстояния от места своего обогащения [24].

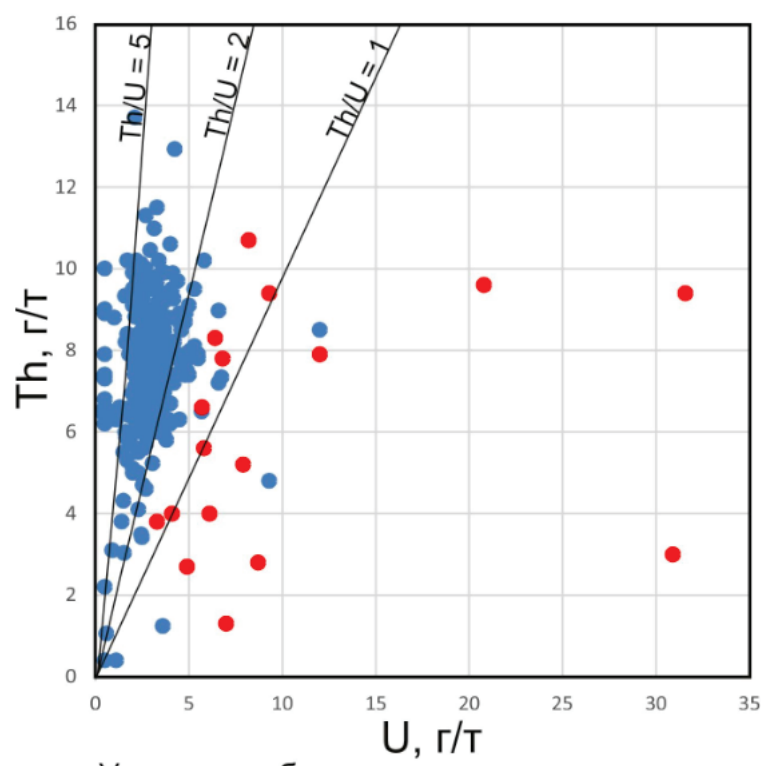

Условные обозначения:

- донные отложения районов Томской области;

- - Осиновско - Бабарыкинская аномальная зона.

Pис.7. Радиогеохимическая характеристика донных отложений Томской области

Fig. 7. Radiogeochemical characteristics of bottom sediments in Tomsk region
В Шегарском районе урановые аномалии пространственно приурочены к гранитоидам позднепалеозойского фундамента.

Для детального изучения Осиновско-Бабарыкинской радиогеохимически аномальной зоны проведен поинтервальный отбор в разрезе вертикального профиля донных осадков отдельных водоемов. Вертикальное распределение урана и тория в донных отложениях водоема в деревне Осиновка Кожевниковского района представлено на рис. 8.

Анализ графиков вертикального распределения большой группы химических элементов в донных отложениях озера, находящегося в деревне Осиновка, позволяет сделать выводы, что все изученные элементы своими средним значениям очень близки или совпадают с региональным фоном для донных отложений. Исключением является уран, средние значения которого превышают среднюю оценку для Томской области

Осиновская урановая аномалия прослеживается и в д. Малиновка Кожевниковскго района. Подпрудный водоем располагается севернее на расстоянии 18 км от д. Осиновка на реке Кумлова. На этой же реке располагается и пруд в д. Осиновке. Вертикальное распределение урана и тория представлено на рис. 9.

Возраст урановой аномалии молодой, так как радиоактивное равновесие между U и Ra не установилось. Это говорит о том, что поступление урана происходило не за счет минеральной массы, а с современными водными растворами. Характер распределения элементов позволяет заключить, что

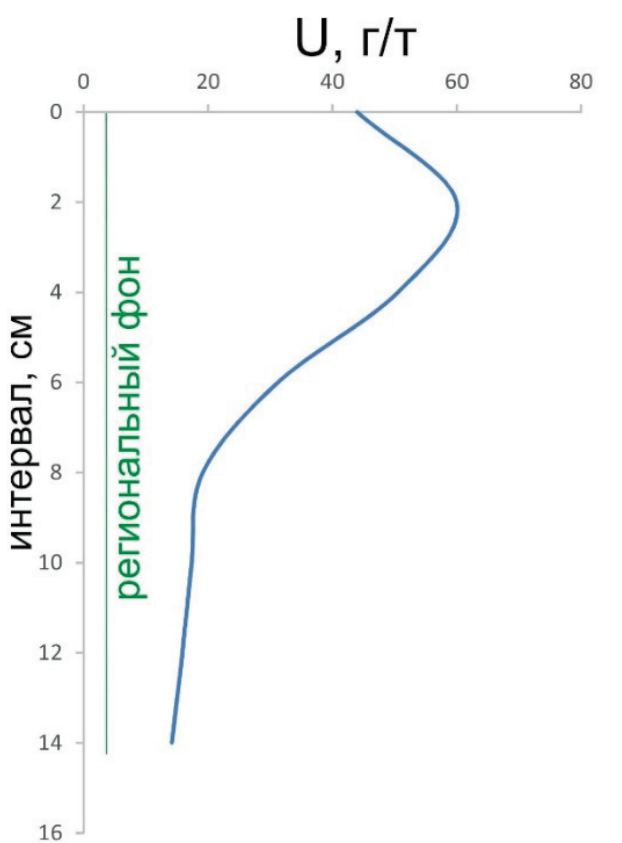

$a / a$

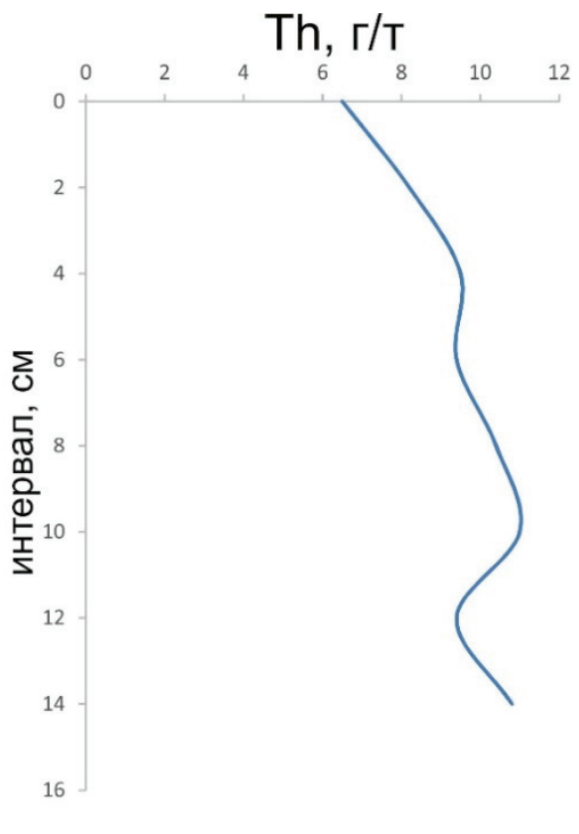

$\sigma / b$

Puc. 8. Вертикальное распределение а) U и б) Th в колонке донных отложений озера в деревне Осиновка

Fig. 8. Vertical distribution of a) $U$ and b) Th in the lake sediments column in Osinovka village 


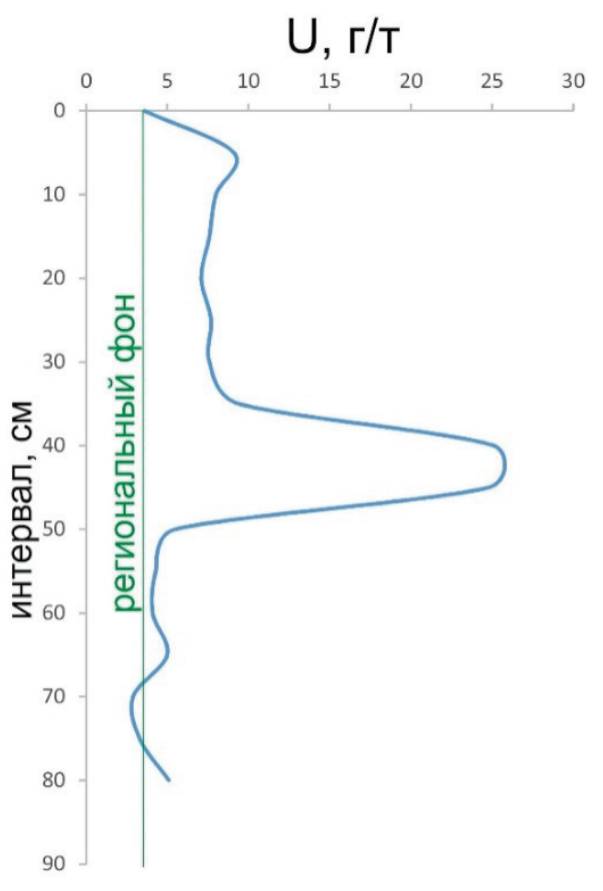

$a / a$

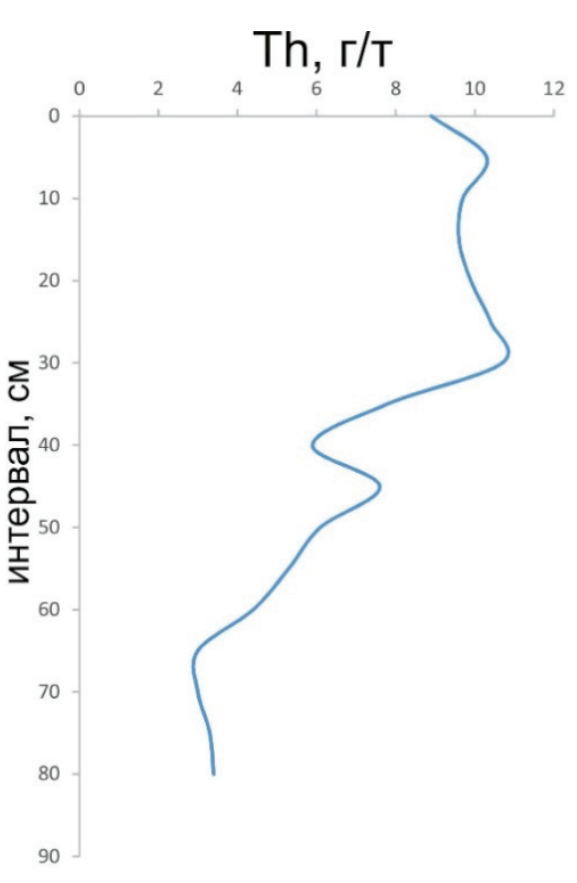

$\sigma / b$

Pис. 9. Вертикальное распределение а) U и б) Тh в колонке донных отложений озера в деревне Малиновка

Fig. 9. Vertical distribution of a) $U$ and $b$ ) Th in the lake sediments column in Malinovka village

урановая аномалия монометальная и, скорее всего, имеет гидрогенное происхождение.

\section{Заключение}

В результате проделанной работы по изучению радиогеохимических особенностей донных осадков озер и искусственных водоемов на территории юга Томской области установлено, что среднее содержание урана и тория в них сопоставимо с кларком для осадочных пород.

Донные отложения исследуемых водоемов имеют высокий коэффициент вариации для урана, что указывает на его неравномерное распределение. При этом торий имеет однородную совокупность. Высокий коэффициент вариации распределения урана обусловлен различными факторами: неоднородным химическим составом вод исследуемых водоемов и региональными радиогеохимическими особенностями области питания бассейна осадконакопления.

Оценка изучения средних содержаний естественных радионуклидов в донных осадках озер и

\section{СПИСОК ЛИТЕРАТУРЫ}

1. Домаренко В.А., Чернев Е.М., Соболев И.С. Возможности обнаружения уранового оруденения гидрогенного типа на востоке Западно-Сибирской плиты // Разведка и охрана недр. 2010. - № 11. - C. 24-32.

2. Рихванов Л.П., Язиков Е.Г., Сухих Ю.И. Эколого-геохимические особенности природных сред Томского района и заболеваемость населения. - Томск: Изд-во Томского политехнического университета, 2006. - 216 с. искусственных водоемов на территории юга Tомской области позволяет резюмировать, что их состав значительно отличается в различных минеральных типах.

Минимальные содержания урана установлены в торфянистом типе, а максимальные - в терригенHOM.

Латеральное распределение урана в донных осадках позволяет выделить зоны с высокими уровнями его концентрирования. Первая зона простирается вдоль южного обрамления Западно-Сибирской плиты. Вторая радиогеохимически аномальная зона концентрации урана пространственно совпадает с полями развития гранитов позднепалеозойского комплекса. Предполагается, что формирование этой аномалии обусловлено разгрузкой подземных вод трещинного типа Колыванского разлома, где установлены аномальные концентрации урана.

Работа выполнена при финансовой поддержке гранта РФФИ № 18-55-80015.

3. Язиков Е.Г., Таловская А.В., Жорняк Л.В. Оценка экологогеохимического состояния г. Томска по данным изучения пылеаэрозолей и почв. - Томск: Издательство Томского политехнического университета, 2010. - 264 с.

4. Aichner B., Herzschuh U., Wilkes H. Influence of aquatic macrophytes on the stable carbon isotopic signatures of sedimentary organic matter in lakes on the Tibetan Plateau // Org Geochem. 2010. - V. 41. - № 7. - P. 706-718.

5. Machowski R., Rzetala M., Rzetala M. Chemical composition of the surface layer of bottom sediments in the northern part of the 
chott el jerid periodic lake in Tunisia // International Multidisciplinary Scientific GeoConference Surveying Geology and Mining Ecology Management, SGEM. - Albena, Bulgaria, 2017. V. 17 . - P. 89-96.

6. Edgington D.N. et al. Sedimentation rates, residence times and radionuclide inventories in Lake Baikal from ${ }^{137} \mathrm{Cs}$ and ${ }^{210} \mathrm{~Pb}$ in sediment cores // Nature. - 1991. - V. 350. - №6319. P. 601-604.

7. Hydro-chemical processes in Lake Qinghai throughout climate warming: in situ investigations of the largest lake in China / C.F. Jin, S.J. Li, H.L. Zhang, J.F. Liu, W. Chen, Y.J. Jiang // Nat Sci. - 2016. - V. 8. - № 12. - P. 574-590.

8. Bu-Li Cui, Xiao-Yan Li Characteristics of stable isotopes and hydrochemistry of river water in the Qinghai Lake Basin, northeast Qinghai-Tibet Plateau, China // Environmental Earth Sciences. 2015. - V. 73. - № 8. - P. 4251-4263.

9. Förstner U., Wittmann G.T.W. Metal pollution in the aquatic en vironment. - Berlin: Springer-Verlag, 1979. - 486 p.

10. Alemdaroglu T., Onur E., Erkakan F. Trace metal levels in surface sediments of Lake Manyas, Turkey and tributary rivers // Int. J. Environ. Stud. - 2003. - № 60. - P. 287-298.

11. Paleo-limnological reconstruction of historical atmospheric lead and mercury deposition at Lake Tahoe, California-Nevada / A.C. Heyvaert, J.E. Reuter, D.G. Sloton, C.R. Goldman // Environ. Sci. Tech. - 2000. - № 34. - P. 3588-3597.

12. Страховенко В.Д. Геохимия донных отложений малых континентальных озер Сибири: дис. ... д-ра геол.-минерал. наук. Новосибирск, 2011. - 307 с.

13. Elevated uranium concentrations in Lake Baikal sediments: burial and early diagenesis / L.M. Och, B. Mueller, C. März et al. // Chemical Geology. - 2016. - V. 441. - P. 92-105.

14. Субетто Д.А., Прыткова М.Я. Донные отложения разнотипных водоемов. Методы изучения. - Петрозаводск: Карельский научный центр РАН, 2016. - 89 с.

15. Иванов А.Ю. Закономерности распределения химических элементов в вертикальном профиле донных отложений слабопроточных водоемов Томского района // Известия Томского политехнического университета. Инжиниринг георесурсов. 2016. - T. 327. - № 2. - C. 88-101.

16. Савичев 0.Г. Водные ресурсы Томской области - Томск: Изд-во Томского политехнического университета, 2010. - 248 с.
17. Судыко А.Ф. Определение урана и тория в природных объектах нейтронно-активационным методом // Радиоактивность и радиоактивные элементы в среде обитания человека: Матер. II Междунар. конф. - Томск: Изд-во «Тандем-Арт», 2004. C. $587-592$.

18. Григорьев Н.А. Среднее содержание химических элементов в горных породах, слагающих верхнюю часть континентальной коры // Геохимия. - 2003. - № 7. - С. 785-792.

19. Рихванов Л.П. Общие и региональные проблемы радиоэкологии. - Томск: Изд-во Томского политехнического университета, 1997. - 384 с.

20. Соболев И.С., Рихванов Л.П., Лященко Н.Г. 0 возможности использования комплекса радиогеохимических методов при прогнозировании и поисках глубокозалегающих урановых месторождений гидрогенного типа // Актуальные проблемы урановой промышленности. - Сборник докладов VI Международной научно-практической конференции - Алматы, Казахстан, 14-16 сент. 2010. - Алматы: Adem Print, 2010. - С. 380-385.

21. Geochemistry of radioactive elements (U, Th) in coal and peat of northern Asia (Siberia, Russian Far East, Kazakhstan, and Mongolia) / S.I. Arbuzov, A.V. Volostnov, L.P. Rikhvanov, A.M. Mezhibor, S.S. Ilenok // Int. J. Coal Geol. - 2011. - V. 86. P. 318-328.

22. Росляков Н.А., Бобров В.А., Белянин Д.К. К вопросу об источниках радионуклидов в торфяниках юга Западной Сибири // Тяжелые металлы и радионуклиды в окружающей среде: Материалы V международной научно-практической конференции, 15-18 октября 2008 г. - Семей: Изд-во Семипалатинского государственного педагогического института, 2008. C. $346-348$.

23. Росляков Н.А., Жмодик С.М., Пахомов В.Г. Естественные радионуклиды в геологической среде Новосибирской области // Радиоактивность и радиоактивные элементы в среде обитания человека. - Томск: Изд-во Томского политехнического университета, 2013. - С. 461-464.

24. Токарев А.Н., Щербаков А.В. Радиогидрогеология. - М.: Государственное научно-техническое издание литературы по геологии и охране недр, 1956. - 263 с.

Поступила: 28.01.2019 2.

\section{Информация об авторах}

Иванов А.Ю., старший преподаватель отделения геологии Инженерной школы природных ресурсов Национального исследовательского Томского политехнического университета.

Арбузов С.И., доктор геолого-минералогических наук, профессор отделения геологии Инженерной школы природных ресурсов Национального исследовательского Томского политехнического университета. 


\title{
GEOCHEMISTRY OF URANIUM AND THORIUM IN BOTTOM SEDIMENTS OF SMALL ARTIFICIAL WATER RESERVOIRS AND LAKES IN THE SOUTH OF THE TOMSK REGION
}

\author{
Andrey Y. Ivanov', \\ Ivanov-13@mail.ru \\ Sergey I. Arbuzov', \\ Siarbuzov@mail.ru \\ 1 National Research Tomsk Polytechnic University, \\ 30, Lenin Avenue, Tomsk, 634050, Russia.
}

The relevance. Radioactive elements are effective markers of the bottom sediments of Tomsk region.

The aim of the research is to study radiogeochemical features of the sediments of small water reservoirs in the south of Tomsk region. The object of the study is the bottom sediments of small reservoirs in the south of Tomsk region.

Methods: detailed sampling of the sediments of small reservoirs, multi-element instrumental neutron activation analysis, and data processing and interpretation by applied statistics methods.

Results. We carried out radio-geochemical study of the sediments of small water reservoirs in the south of Tomsk region. Mean contents of uranium and thorium in the sediments of small reservoirs in the south of the Tomsk region were estimated. The studies showed that the uranium and thorium contents depend on the type of sediments. The highest uranium content was found in the terrigenous type of the sediments, the lowest one was found in the peat. Two zones with high uranium content were found. The first zone is spatially coinsine with Kozhevnikovsky and Shegarsky districts of Tomsk region. Osinovo-Babarykinskaya anomalous zone of uranium accumulation in this region is clearly visible, which is well seen in the submeridional direction. Within Kozhevnikovo district, it can be associated with underground water discharge in the area of the Kolyvanskiy fault. In Shegarsky district, the high uranium contents spatially relate to granitoids of the late Paleozoic Foundation. The second zone of uranium accumulation extends along the southern frame of the West Siberian plate within the Kuznetsk-Alataussky block.

\section{Key words:}

Bottom sediments, uranium and thorium, radiogeochemical studies, zone of anomalous uranium accumulation, vertical distribution.

The research was financially supported by the RFBR grant no. 18-55-80015.

\section{REFERENCES}

1. Domarenko V.A., Chernev E.M., Sobolev I.S. Vozmozhnosti obnaruzheniya uranovogo orudeneniya gidrogennogo tipa na vostoke Zapadno-Sibirskoy plity [Detection capabilities of hydrogenic uranium mineralization in the East of the West Siberian plate]. Exploration and protection of subsoil, 2010, no. 11, pp. 24-32.

2. Rikhvanov L.P., Yazikov E.G., Sukhikh Yu.I. Ekologo-geokhimicheskie osobennosti prirodnykh sred Tomskogo rayona i zabolevaemost naseleniya [Ecogeochemical features of natural environments of Tomsk region and diseases of the population]. Tomsk, TPU Publ. house, 2006. $216 \mathrm{p}$.

3. Yazikov E.G., Talovskaya A.V., Zhornyak L.V. Otsenka ekologogeokhimicheskogo sostoyaniya g. Tomska po dannym izucheniya pyleaerozoley i pochv [Assessment of ecological and geochemical state of Tomsk city according to the study of dust aerosols and soils]. Tomsk, TPU Publ. house, 2010. 264 p.

4. Aichner B., Herzschuh U., Wilkes H. Influence of aquatic macrophytes on the stable carbon isotopic signatures of sedimentary organic matter in lakes on the Tibetan Plateau. Org Geochem., 2010, vol. 41, no. 7, pp. 706-718.

5. Machowski R., Rzetala M., Rzetala M. Chemical composition of the surface layer of bottom sediments in the northern part of the chott el jerid periodic lake in Tunisia. International Multidisciplinary Scientific GeoConference Surveying Geology and Mining Ecology Management, SGEM. Albena, Bulgaria, 2017. Vol. 17, pp. 89-96.

6. Edgington D.N. Sedimentation rates, residence times and radionuclide inventories in Lake Baikal from $137 \mathrm{Cs}$ and $210 \mathrm{~Pb}$ in sediment cores. Nature, 1991, vol. 350, no. 6319, pp. 601-604.

7. Jin C.F., Li S.J., Zhang H.L., Liu J.F., Chen W., Jiang Y.J. Hydro-chemical processes in Lake Qinghai throughout climate war- ming: in situ investigations of the largest lake in China. Nat Sci., 2016, V.8. - № 12. - P. 574-590.

8. Bu-Li Cui, Xiao-Yan Li. Characteristics of stable isotopes and hydrochemistry of river water in the Qinghai Lake Basin, northeast Qinghai-Tibet Plateau, China. Environmental Earth Sciences, 2015, vol. 73, no. 8, pp. 4251-4263.

9. Förstner U., Wittmann G.T.W. Metal pollution in the aquatic environment. Berlin, Springer-Verlag, 1979. 486 p.

10. Alemdaroglu T., Onur E., Erkakan F. Trace metal levels in surface sediments of Lake Manyas, Turkey and tributary rivers. Int. J.Environ. Stud., 2003, no. 60, pp. 287-298.

11. Heyvaert A.C., Reuter J.E., Sloton D.G., Goldman C.R. Paleolimnological reconstruction of historical atmospheric lead and mercury deposition at Lake Tahoe, California-Nevada. Environ. Sci. Tech., 2000, no. 34, pp. 3588-3597.

12. Strakhovenko V.D. Geokhimiya donnykh otlozheniy malykh kontinentalnykh ozer Sibiri. Dis. Dokt. nauk [Geochemistry of bottom sediments of small continental lakes of Siberia. Dr. Diss.]. Novosibirsk, 2011. $307 \mathrm{p}$.

13. Och L.M., Mueller B., März C. Elevated uranium concentrations in Lake Baikal sediments: Burial and early diagenesis. Chemical Geology, 2016, vol. 441, pp. 92-105.

14. Subetto D.A. Prytkova M.Ya. Donnye otlozheniya raznotipnykh vodoemov. Metody izucheniya [Bottom sediments of different types of water reservoirs. Research methods]. Petrozavodsk, Karelskiy nauchny tsentr RAN, $2016.89 \mathrm{p}$.

15. Ivanov A.Yu. Regularities of distribution of chemical elements in the sediment vertical profiles of low-flow reservoirs of Tomsk region. Bulletin of the Tomsk Polytechnic University, 2016, vol. 327 , no. 2, pp. 88-101. 
16. Savichev 0.G. Vodnye resursy Tomskoy oblasti [Water resources of the Tomsk region]. Tomsk, Tomsk Polytechnic University Publ. house, 2010. 248 p.

17. Sudyko A.F. Opredelenie urana i toriya v prirodnykh obektakh neytronno-aktivatsionnym metodom [Determination of uranium and thorium in natural objects by neutron activation method]. $R a$ dioaktivnost $i$ radioaktivnye elementy $v$ srede obitaniya cheloveka [Radioactivity and radioactive elements in the human environment]. Tomsk, Tandem-Art Publ., 2004. pp. 587-592.

18. Grigorev N.A. Srednee soderzhanie khimicheskikh elementov v gornykh porodakh, slagayushchikh verkhnyuyu chast kontinentalnoy kory [Mean contents of chemical elements in the rocks composing the upper part of the continental crust]. Geokhimiya, 2003, no. 7, pp. 785-792.

19. Rikhvanov L.P. Obshchie $i$ regionalnye problemy radioekologii [General and regional problems of radioecology]. Tomsk, TPU Publ. house, 1997. 384 p.

20. Sobolev I.S., Rikhvanov L.P, Lyashchenko N.G. 0 vozmozhnosti ispolzovaniya kompleksa radiogeokhimicheskikh metodov pri prognozirovanii i poiskakh glubokozalegayushchikh uranovykh mestorozhdeniy gidrogennogo tip [0n possibility of using the complex of radiogeochemical methods for forecasting and exploration of deep hydrogenic uranium deposits]. Aktualnye problemy uranovoy promyshlennosti [Actual problems of the uranium industry]. Almaty, Adem Print, 2010. pp. 380-385.

21. Arbuzov S.I., Volostnov A.V., Rikhvanov L.P., Mezhibor A.M., Ilenok S.S. Geochemistry of radioactive elements (U, Th) in coal and peat of northern Asia (Siberia, Russian Far East, Kazakhstan, and Mongolia). Int. J. Coal Geol., 2011, vol. 86, pp. $318-328$.

22. Roslyakov N.A., Bobrov V.A., Belyanin D.K. K voprosu ob istochnikakh radionuklidov v torfyanikakh yuga Zapadnoy Sibiri [The issue of sources of radionuclides in the peatlands of the south of Western Siberia]. Tyazhelye metally $i$ radionuklidy $v$ okruzhayushchey srede [Heavy metals and radionuclides in the environment]. Semey, SGPI Publ. house, 2008. pp. 346-348.

23. Roslyakov N.A., Zhmodik S.M., Pakhomov V.G. Estestvennye radionuklidy v geologicheskoy srede Novosibirskoy oblasti [Natural radionuclides in the geological environment of Novosibirsk region]. Radioaktivnost i radioaktivnye elementy $v$ srede obitaniya cheloveka [Radioactivity and radioactive elements in the human environment]. Tomsk, TPU Publ. house, 2013. pp. 461-464.

24. Tokarev A.N., Shcherbakov A.V. Radiogidrogeologiya [Radiohydrogeology]. Moscow, GNTI Publ., 1956. 263 p.

Received: 28 January 2019.

\section{Information about the authors}

Andrey Y. Ivanov, senior lecturer, National Research Tomsk Polytechnic University.

Sergey I. Arbuzov, Dr. Sc., professor, National Research Tomsk Polytechnic University. 